\title{
BMJ Open Cute as candy: a qualitative study of perceptions of snus branding and package design among youth in Norway
}

\author{
Janne Scheffels, Ingeborg Lund
}

To cite: Scheffels J, Lund I. Cute as candy: a qualitative study of perceptions of snus branding and package design among youth in Norway. BMJ Open 2017;7:e012837. doi:10.1136/bmjopen-2016012837

- Prepublication history for this paper is available online. To view these files please visit the journal online (http://dx.doi.org/10.1136/ bmjopen-2016-012837).

Received 27 May 2016 Revised 29 November 2016 Accepted 17 January 2017

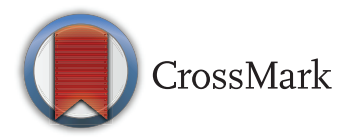

Department of Drug Policy, Norwegian Institute of Public Health, Oslo, Norway

Correspondence to Dr Janne Scheffels; janne.scheffels@fhi.no

\section{ABSTRACT}

Objectives: Snus use has increased among youth in Norway in recent years and is now more prevalent than smoking. Concurrently, a range of new products and package designs have been introduced to the market. The aim of this study was to explore how youth perceive snus branding and package design, and the role, if any, of snus packaging on perceptions of appeal and harm of snus among youth.

Participants: Adolescent tobacco users and nonusers $(\mathrm{N}=35)$ ages $15-17$ years.

Design: We conducted interviews among 6 focus groups (each with 4-7 participants). Participants were shown snus packages with a variety of designs and with different product qualities (flavour additives, slim, regular, white and brown sachets) and group discussions focused on how they perceived packages and products. The focus group discussions were semistructured using a standard guide, and analysed thematically.

Results: The participants in the focus groups narrated distinct images of snus brands and associated user identities. Package design elements such as shapes, colours, images and fonts were described as guiding these perceptions. Packaging elements and flavour additives were associated with perceptions of product harm. The appeal of flavoured snus products and new types of snus sachets seemed to blend in with these processes, reinforcing positive attitudes and contributing to the creation of particular identities for products and their users.

Conclusions: The findings indicate that packaging is vital to consumer's identification with, and differentiation between, snus brands. In view of this, snus branding and packaging can be seen as fulfilling a similar promotional role as advertising messages: generating preferences and appeal.

\section{INTRODUCTION}

Snus (a traditional Swedish-type oral moist snuff) has a long product history and use tradition among men in Scandinavia. In Norway, snus sales were low until around 1990, when the traditional moist snuff was reintroduced as a new, drier product packed in small sachets. Since then, snus use has increased dramatically, particularly among

\section{Strengths and limitations of this study}

- The first study to explore perceptions of snus branding and packaging in Scandinavia, where snus use is most common.

- Exploratory design provides insight into what the study group perceives as important regarding snus branding and packaging.

- Small sample size does not provide representative data, although given the exploratory nature of the study, this was not our aim.

youth. In $2016,25 \%$ of $16-24$ year olds were daily or occasional snus users. Daily use was slightly more prevalent among males (21\%) than females $(17 \%)$. In comparison, the prevalence of daily and occasional smoking in this age segment was $3 \%$ and $13 \%$ respectively. ${ }^{1}$ The only country with a similar level of snus use is Sweden, that was granted an exemption from the ban on sale of snus in the European Union (EU) as a condition of their membership treaty. Norway is not a member of the EU, and snus is legally sold and used. In other countries where snus is marketed, like the USA, the prevalence of snus use is low. ${ }^{2}{ }^{3}$ Massive marketing of snus in the USA, including new products from companies also producing cigarettes, such as Camel and Marlboro snus, ${ }^{5}$ has however given rise to some concern that snus use may be escalating also outside Scandinavia. While the majority of adult snus users in Norway are former smokers, the majority of young users started without prior smoking. Consequently, the public health effects from adolescent use could be quite different from that of adult use, as switching to snus implies a substantial harm reduction for individual smokers while initiation of snus use implies an increased risk of harm for non-tobacco users. ${ }^{7} 8$ Similar to cigarettes, the minimum age for purchasing snus in Norway is 18 and warning labels are mandatory, although for snus a smaller sized, non-graphic version, with a more moderated textual content, is 
used. Both products are sold in regular shops, and no form of advertising is allowed, including point of sale advertising ban. ${ }^{9}$ During the period of increase in snus use in Norway, a range of new snus brands and products have been introduced to the market, including a wide variety of products with flavour additives such as mint, fruit or chocolate and with different shapes and colours of snus sachets. For example, Swedish Match, the market-leading snus-producing company in Scandinavia, increased its brand portfolio from 22 variants in 2002 to 180 variants 6 years later. ${ }^{10}$ Snus packages, traditionally dark-coloured and round boxes that resemble an ice hockey puck, are today available in a wide variety of colours and designs. In countries with comprehensive restrictions on advertising, tobacco packaging is the most prominent form of marketing. Through the use of colour, fonts, images and trademarks, packages can project a brand image that says something about the user of the product and about product qualities. ${ }^{11}$ Research has demonstrated how light-coloured or white packages are perceived as less harmful than darker packages, ${ }^{12} 13$ and how notions of relative harm can be strengthened by variant descriptor names denoting colour. ${ }^{14}{ }^{15}$ A systematic review of research on cigarette packaging has indicated that such processes can be counteracted by standardising cigarette pack appearance. ${ }^{16}$ This conclusion has been largely supported by recent evaluation results from Australia, ${ }^{17} 18$ where legislation mandating standardised packaging of tobacco was implemented in 2012. It has also been indicated by experimental research that cigarette packaging developed to appeal particularly to young women, for example, packages looking like lipstick boxes, are perceived as appealing and as less harmful than more standard cigarette packages, because of their smaller size and likeness to cosmetics. ${ }^{19}$ Similarly, studies of flavoured cigarettes has indicated that these products often are perceived as less harmful and as more attractive than regular cigarettes, in particular among young women. ${ }^{20} 21$

While research about cigarette packaging has increased over the latest decade, only a few studies have explored how consumers perceive snus packaging and product design. In the USA, Choi et $a l^{22}$ found that youth perceived snus products as attractive, thought the packages were more modern than cigarette packages and found them cleverly designed to attract attention.
Liu $e t a l^{23}$ similarly found that the colour, design and size of smokeless tobacco packaging appealed to adults and adolescents and influenced purchase decisions. Adkison $e t a l^{4}$ analysed the impact of snus packaging on perceptions of product appeal and beliefs about health risk in a US sample, and concluded that branded packages were seen as more appealing than packages without corporate branding, and that youth and young adults were more likely than adults to indicate that package elements affected their perceptions of appeal and risk associated with the use of snus. To date, there have been no published studies exploring the perceptions of snus branding and packaging in Scandinavia, where snus use is most common and has been on the market for some time.

In order to provide insight into youth's perceptions of snus branding and package design in a mature snus market, we recruited young tobacco users and non-users of both products to participate in a series of focus group discussions. We addressed the following research question: How do young tobacco users and non-users perceive snus branding, packaging and product design? More specifically focusing on the upswing in adolescent snus use, we also sought to explore the role, if any, of snus packaging on perceptions of appeal and harm of snus among youth.

\section{METHODS}

Six focus group interviews (4-7 participants in each group) of male and female tobacco users and non-users $(\mathrm{N}=35)$ aged $15-17$ years were undertaken. We recruited the participants into the different groups based on their self-definition as smokers, snus users or non-users of tobacco (table 1). In four of the focus groups, all participants defined themselves as snus users or smokers, while in two, they defined themselves as non-users of both products. In the focus group discussions, it was revealed that many of the smokers had experience with using both products, ranging from having tried snus once or twice, to using snus when cigarettes were not available to them, to regular dual use. Also, some of the snus users smoked occasionally, in particular at parties, and most had tried smoking at least once. These patterns were not unexpected, given that dual use of cigarettes and snus is common among youth in Norway. ${ }^{25}{ }^{26} \mathrm{~A}$ recent survey

\begin{tabular}{lllll}
\multicolumn{2}{l}{ Table 1 } & Overview of groups and participants & & \\
\hline Group number & Number of participants & Self-defined tobacco use status & Age range (years) & Gender \\
\hline 1 & 7 & Non-users & $16-17$ & 6 girls, 1 boy \\
2 & 5 & Tobacco users & $16-17$ & 3 girls, 2 boys \\
3 & 4 & Tobacco users & $16-17$ & 4 boys \\
4 & 6 & Tobacco users & $16-17$ & 6 girls \\
5 & 6 & Non-users & $15-16$ & 6 girls \\
6 & 7 & Tobacco users & $16-17$ & 4 girls, 3 boys \\
Total & 35 & 22 tobacco users, 13 non-users & $15-17$ & 25 girls, 10 boys \\
\hline
\end{tabular}


Table 2 Overview of packages

\begin{tabular}{llll}
\hline Brand & Brand variant & Package design & Flavour additive \\
\hline General & Classic Loose & Dark colour, gold decor & None \\
General & Classic Portion & Dark colour, red decor & None \\
The Lab & 06 Extra Strong slim portion & Light colour, red decor & None \\
The Lab & Fresh Lemon slim white portion & Light colour, yellow and white decor & Lemon \\
Skruf & Fresh White slim portion & Light colour, light blue decor & Mint \\
Skruf & Nord 66 Strong portion & Dark colour, green decor & None \\
Nick \& Johnny & Radical Red Xtra strong & Dark colour, purple decor & Chili \\
Nick \& Johnny & Captain Yankee Xtra strong & Dark colour, red and blue decor & None \\
Catch & White Spearmint Slim & Light colour, light blue decor & Spearmint \\
Mocca & Mint White miniportion & Light colour, pink decor, smaller size package & Mint \\
\hline
\end{tabular}

among 15-year-old adolescents showed that almost half of all tobacco users were dual users of snus and cigarettes. $^{27}$ As this means that also self-defined smokers were likely to be familiar with snus and snus branding, 'we decided to treat both groups of tobacco users as one in the reporting of results. In the groups that self-defined as non-users of tobacco, we learnt during the discussions that some had tried snus or cigarettes. However, as the group discussions indicated that the distinction between use and non-use of tobacco was important to their self-understanding, we decided to retain the label non-users in our reporting of results.

Non-tobacco users were included in the sample in order to compare their opinions and reflections with those of tobacco users, and to explore more directly the appeal of snus packages to potential new users. All participants were recruited through three initial contacts who were aged 15, 16 and 17 years, respectively, and who were members of the two researchers' social networks. These contacts attended three different schools and recruited participants from their social networks, who in turn recruited additional participants from their circles of friends and acquaintances. The total sample included individuals from nine different junior and senior high schools in Oslo. The three initial contacts received remuneration of 50 Norwegian kroner for each participant they recruited. The focus group participants received a gift voucher of 300 Norwegian kroner as compensation for their study participation.

The focus group interviews were semistructured using a standard guide. The groups were conducted in Norwegian, and only the quotes used in the paper were translated into English, with validation from both authors. All participants were asked about experience with tobacco use and general perceptions of snus use and smoking, including ideas about typical users. Ten snus packages were then introduced as stimuli for the discussions. The participants were asked how they perceived the products before them, with regard to appeal and potential for harm to health. They were also asked to associate typical users of the different packages. The packages were chosen to represent a variety of designs, colours and shapes, including light-coloured and dark- coloured packages and packages in different sizes. We included also packages with and without flavour additives and packages with white and brown sachets (see table 2 for an overview of packages). Summing up, the moderator asked the groups to discuss the role of branding and packaging for the appeal of snus.

The group sessions lasted an average of $60 \mathrm{~min}$. Each was audio recorded, transcribed and analysed using the HyperResearch software package for qualitative analysis. Analyses was performed systematically, ${ }^{28}$ beginning with several rounds of transcript reading followed by thematic coding in HyperResearch. Both authors read all transcripts, the first author did the initial coding and the coding was then discussed between the authors before they were organised into larger themes. The codes were reworked both by setting up charts of patterns of occurrence, as well as by close reading of coded text for themes and possible connections between themes. Informed participant consent, and parental consent for those under 16 years, was obtained from all participants. Quotations are marked with focus group number and the speaker's tobacco use status and gender.

\section{RESULTS}

\section{Snus package design communicates identity}

The participants generally described positive associations with snus use, including user typologies like young, social and popular. When presented with the stimulus snus packages, distinct user identities were narrated in relation to each of them. Gender, age and social class were important associations, and package design elements such as colours and fonts stood out as guiding these perceptions; for example, they perceived darker packages as masculine and lighter coloured packages as feminine. In gender mixed groups as well as groups with boys or girls only, packaging and gender identity was discussed in an engaged way. The participants generally preferred packages they associated with their own gender, with some exceptions made for the most stereotypical 'feminine packages', such as Mocca. The pink colour, ornamented font, small and rounded shape and metallic look was described as 'too much', in the sense that it was too 'girly', by some female participants; 
however, among others-in particular females who did not use snus themselves-this design was valued. They liked the colour and that the package did not look like snus to them, but like candy or make-up. The Lab 06 snus was the most popular brand among the boys and the brand identity described by non-users and females confirmed that this was understood to be a typical brand for young males. Some brands, such as General snus, were perceived as brands for older people while others, such as Lab 06, for youth. Associations between packaging and lifestyle or social class were frequent in most groups and the user identities linked to these were most often positively loaded. For example, regarding the black and gold-coloured General Portion snus package, "that one is the snus for the guy who drives his Lexus to his posh office" (group 6, male tobacco user), or Lab Lemon Fresh snus, "this is the snus for those very energetic people. Sporty, happy people!" (group 5, female non-user). In the discussion following the latter statement, the other girls in the group agreed with this interpretation and commented that it was the light colour, the brand name (Fresh) and the flavour additive that generated this association.

The participants differentiated clearly between snus brands with reference to package designs: "Skruf looks like it's good for your health, the Lab Fresh looks like sport or fitness snus and those Nick \& Johnny look like they make you a good skater. The loose General, it looks like it will destroy you" (group 5, female non-user). In one group of tobacco users, some of the participants talked about how they interpreted snus packages as carrying more meaning than cigarette packages: "The brand of snus that you use kind of define what kind of person you are, more than cigarette brands even, because the selection of brands and products is bigger" (group 2, female tobacco user). The same view was stated in both the groups of self-defined non-users. Snus packages were seen as more diverse because of the package design, but also because of descriptors stating product strength and flavour additives that cigarettes do not have in Norway: "I can't see from cigarette packages which ones are stronger, and there are no flavours like lemon or strawberry" (group 5, female non-user).

The tobacco users described also how using particular brands of snus or cigarettes was an element in defining what social group they were part of or wanted to be associated with. In this, tobacco brand associations and distinctions between them stood out as serving as a way of signalling social identity. One of the participants stated her view on the social meaning of snus branding in this way:

It seems also like those, The Lab 06 and those products, are more like, trendy. That you are not a real snus user if you do not use those. Just like, you go to Starbucks, you don't go to like, Waynes Coffee or Kaffebrenneriet, if you want a frappe, you buy it at Starbucks because it is a brand. (Group 6, female tobacco user)
Across the focus groups with tobacco users, snus branding was described as contributing to increasing the competitive position of some products, and as constituting the core of the snus user's identity. Differentiation between snus brands, and identification with some more than others, stood out as the dynamics of this process. While most of the non-users expressed confidence in that they themselves would not start, they believed that many other non-users could be tempted to try snus because of the wide variety in brands and package designs on the market: "You see the package first, and it becomes an advertisement, kind of" (group 1, female non-user).

\section{Package design and perceptions of product qualities}

Package design elements were frequently associated with product qualities, with the most common being product strength. Smaller, lighter coloured packages and packages with rounded edges were perceived as less strong than products packed in darker, sharp-edged boxes. The colour white, particularly when combined with green or blue décor or letters, was seen as signalling a milder product. In some cases, packages were differentiated by potential for harm directly, such as when a group of boys described the dark General snus packages as looking rougher, more masculine and more harmful, in contrast to lighter coloured packages.

Associations with products other than tobacco, such as candy, cosmetics or chewing gum were common across interviews, and the interviewees described pack colours, fonts in brand names and flavour additives as generating these associations: "Because it says 'spearmint', you could think; oh, it's candy" (group 4, female tobacco user). In one of the non-user groups, the colourful Nick \& Johnny snus package was described as looking like "that chewing gum, Hubba Bubba, that we used to like when we were younger" (group 1, female non-user). In many cases, such associations with other products seemed intertwined with perceptions of harm. For example, the light grey Skruf White box was often interpreted as fresh, mild and "looking sterile, or like skin cream" (group 6, female tobacco user). The white Catch Spearmint package was associated with medicines: "Looks like the dentist gave it to you. It would fit well in a chemist shop" (group 6, male tobacco user). In some cases, the linkage between associations to products other than tobacco and perceptions of product harm were explicit: "The candy snus looks not to be dangerous at all, I mean, it's not like it's really candy, but it is as dangerous as candy" (group 3, male tobacco user). These associations with products other than tobacco thus seemed to add to more general diversification between products with regard to potential for harm to health. In addition, associations with candy and other products that are appealing to youth appeared to contribute to the appeal of snus among the study participants.

Flavour additives and snus sachet colour and shape Flavour additives and sachet colour and shape was not a theme in the interview guide, but in all the focus 
groups, one or more participants spontaneously brought this up as important to how they perceived different snus brands and products. Flavoured snus was perceived as particularly appealing to youth and to new users: "Bright colours appeal to the young, and taste, not the least. Old people are not that interested in, kind of, tastes like lemon and that" (group 2, male tobacco user). They explained their opinion by stating that flavour additives made the tobacco taste less prominent and in this way more appealing to inexperienced users. In addition, some perceived that youth could be attracted by the notion of a milder product created by flavour additives such as mint and fruit.

In the groups of self-defined non-users, all participants stated that they were determined not to use tobacco, and that nice package design would not influence their stance. Nevertheless, they would sometimes express more ambiguity, and statements indicating curiosity to try snus usually related to flavour:

I would think that one was really mild, so I could try it, because it's not dangerous at all. In particular when it's written on it, like, taste, and it says lemon. Lemon, that sounds good. (Group 1, female non-user)

In the tobacco user groups, many also talked about sachet colour and shape as important for the appeal of snus to young users. Slim snus sachets were described as preferable for youth in particular ('snus for starters'), since they are less visible during use:

It doesn't show so much that you are using snus. It's for those people who, kind of, just want snus, but don't want to take the consequences of it, then. (Group 6, female tobacco user)

Slim sachets were perceived as practical, since most youths use snus without permission from parents and go to schools where snus use is not permitted. Some participants also said that slim sachets, particularly if they were also white (as opposed to brown), were less visible, and gave the impression that they contained a product that was less harmful to health. The statement above may indicate a similar view; not wanting to 'take the consequences' of snus use could relate to health consequences and social consequences.

\section{DISCUSSION}

All focus group participants described distinct snus brand images and packaging elements such as colours, letter fonts or shape or size of the package appeared to be essential in the shaping of these images. Differentiation between snus brands, and the identification with some more than others, stood out as essential for the processes in which snus use became important for these young study participants. The findings showed also how perceptions of some products as less harmful than others and the appeal of flavour additives and new types of snus sachets seemed to blend in with these processes, reinforcing positive attitudes and contributing to the creation of particular identities for products and their users. While all non-users expressed that they had no intention to start using tobacco, and that snus packaging was not very likely to affect their decision, they did think that other non-users could be attracted to snus by the variety of brands and packages available. This could be related to how people generally tend to believe that others are more likely to be affected by persuasive communication than they themselves are. ${ }^{29}$

A recent qualitative study among young snus users from Sweden showed that identity development was of major importance when adolescents started using snus. These snus users felt that males could confirm their masculinity by using snus and associated snus use with craftsman professions such as carpenters and car mechanics. The snus package was seen as an attribute of this identity, which created a feeling of belonging. ${ }^{30}$ In the current study, perceptions of a typical snus user were much more diverse and included urban, middle class and feminine typologies. Studies of tobacco industry strategies from the USA have shown how smokeless tobacco manufacturers such as R.J. Reynolds and Phillip Morris have invested in research, product development and marketing for decades, aiming to attract new consumer groups. While the main target group was initially low-income males (portrayed in advertising as 'hard working'), they also targeted more urban, female, smokeless tobacco users with their marketing strategies after $1990 .^{31}$ In Scandinavia, tobacco advertising has been banned for more than 40 years. Our findings indicate, however, that branding and package design to some extent can fulfil a similar promotional role as advertising messages, creating preferences and differentiation between brands and product types. ${ }^{32}$ In addition to gender, age and social status appeared as important distinctions in the focus group participants' conceptions of and identification with snus brand images.

Our analyses indicate also that snus package design was seen as communicating information about product strength, and that packages with light colours were perceived as less harmful than darker packages. Flavoured products in candy-like boxes were perceived positively, in particular among non-users, and flavour additives (eg, mint or fruit) seemed also to contribute to ideas of product strength and harm. Similarly, product qualities and appeal were attributed to the colour and shape of snus sachets. This is similar to studies of combustible tobacco, where flavour additives have been shown to influence cigarette appeal and make the initial experience of smoking less aversive and more appealing to youth. $^{33}{ }^{34}$ Experimental studies of cigarette packaging have shown how standardising colours can reduce false beliefs about some cigarette products being less harmful to health than others, ${ }^{16}$ and that removing flavour descriptors from cigarette packages can make them less appealing to young women. ${ }^{35}$ Similar conclusions have 
been drawn from studies exploring the potential of dissuasive cigarette sticks. ${ }^{36}$

This study has several limitations. Given the small sample size, the findings are not generalisable to wider youth populations, although given the exploratory nature of the study, this was not our aim. The sampling of participants through peer networks may have limited the variety of beliefs expressed in the focus groups. While young people's perceptions of snus packaging were influenced by design features such as colour, fonts and pack shape, the study gives no direct insight into whether this would impact on brand choice or snus use behaviour. Future studies could consider evaluating how snus branding and package design affects perceptions of appeal and health risk by using experimental survey study design. The exploration of how young people themselves talk about how they perceive snus branding and package design presented in this study can, however, provide useful qualitative information to understand the processes snus branding works through.

Since standardised tobacco packaging was introduced in Australia in 2012, bills mandating this regulation have been passed in several European countries, including Norway. The results from this study indicate that snus branding and packaging play a vital role in the appeal of snus among young people and, consequently, points towards the utility of including snus in regulations of tobacco packaging in markets where this product is sold.

Contributors JS conducted the data collection, primary data analysis and manuscript preparation, and revision, supported by intellectual contributions from IL. The study design was developed in cooperation between JS and IL, and both authors approved the final manuscript.

Funding This research received no specific grant from any funding agency in the public, commercial or not-for-profit sectors.

Competing interests None declared.

Ethics approval The Norwegian Centre for Research Data approved the study proposal, reference number 34433.

Provenance and peer review Not commissioned; externally peer reviewed.

Data sharing statement No additional data are available.

Open Access This is an Open Access article distributed in accordance with the Creative Commons Attribution Non Commercial (CC BY-NC 4.0) license, which permits others to distribute, remix, adapt, build upon this work noncommercially, and license their derivative works on different terms, provided the original work is properly cited and the use is non-commercial. See: http:// creativecommons.org/licenses/by-nc/4.0/

\section{REFERENCES}

1. Norwegian Tobacco Statistics, 2016. https://helsedirektoratet.no/ folkehelse/tobakk-royk-og-snus/statistikk-om-royking-bruk-av-snusog-e-sigaretter (accessed 16 March 2017).

2. Eriksen M, Mackay J, Ross H. The tobacco Atlas. American Cancer Society, 2013.

3. Zhu SH, Gamst A, Lee M, et al. The use and perception of electronic cigarettes and snus among the US population. PLOS ONE 2013;8: e79332.

4. Rogers JD, Biener L, Clark PI. Test marketing of new smokeless tobacco products in four US cities. Nicotine Tob Res 2010;12: 69-72.
5. Timberlake DS, Pechmann C, Tran SY, et al. A content analysis of Camel Snus advertisements in print media. Nicotine Tob Res. 2011;13:431-9.

6. Lund KE, Scheffels J, McNeill A. The association between use of snus and quit rates for smoking: results from seven Norwegian cross-sectional studies. Addiction 2011;106:162-7.

7. Scientific Committee on Emerging and Newly Identified Health Risks (SCENIHR). Health effects of smokeless tobacco products. Brussels, Belgium: European Commission, Health \& Consumer Protection Directorate-General, 2008. http://ec.europa.eu/health/ph risk/committees/04_scenihr/docs/scenihr_o_013.pdf (accessed 25 Oct 2015).

8. Levy DT, Mumford EA, Cummings KM, et al. The relative risks of a low-nitrosamine smokeless tobacco product compared with smoking cigarettes: estimates of a panel of experts. Cancer Epidemiol Biomarkers Prev 2004;13:2035-42.

9. Scheffels J, Lavik R. Out of sight, out of mind? Removal of point-of-sale tobacco displays in Norway. Tob Control 2013;22: e37-42.

10. Consultation memorandum: proposal to implement standardized packaging of tobacco in Norway. Norwegian Department of Health, 2015. https://www.regjeringen.no/contentassets/ 7066e0ea25d9478ba3e354f50b6a2317/horingsnotat standardiserte tobakkspakninger_fctc_art53_170315.pdf (accessed 16 March 2017).

11. Wakefield M, Morley $\mathrm{C}$, Horan JK, et al. The cigarette pack as image: new evidence from tobacco industry documents. Tob Control 2002;11(Suppl 1):i73-80.

12. Bansal-Travers $M$, Hammond D, Smith $P$, et al. The impact of cigarette pack design, descriptors, and warning labels on risk perception in the US. Am J Prev Med 2011;40:674-82.

13. Hammond D, Parkinson $C$. The impact of cigarette package design on perceptions of risk. J Public Health (Oxf) 2009;31:345-53.

14. Mutti S, Hammond D, Borland R, et al. Beyond light and mild: cigarette brand descriptors and perceptions of risk in the International Tobacco Control (ITC) Four Country Survey. Addiction 2011;106:1166-75.

15. Borland R, Savvas S. The effects of variant descriptors on the potential effectiveness of plain packaging. Tob Control 2014;23:58-63.

16. Stead M, Moodie C, Angus K, et al. Is consumer response to plain/ standardised tobacco packaging consistent with framework convention on tobacco control guidelines? A systematic review of quantitative studies. PLOS ONE 2013;8:e75919.

17. Wakefield M, Coomber K, Zacher M, et al. Australian adult smokers' responses to plain packaging with larger graphic health warnings 1 year after implementation: results from a national cross-sectiona tracking survey. Tob Control 2015;24(Suppl 2):ii17-25.

18. White V, Williams T, Wakefield M. Has the introduction of plain packaging with larger graphic health warnings changed adolescents perceptions of cigarette packs and brands? Tob Control 2015;24 (Suppl 2):ii42-9.

19. Ford A, Moodie C, Purves R, et al. Adolescent girls and young adult women's perceptions of superslims cigarette packaging: a qualitative study. BMJ Open 2015;6:e010102.

20. Anderson SJ. Marketing of menthol cigarettes and consumer perceptions: a review of tobacco industry documents. Tob Control 2011;20(Suppl 2):ii20-8.

21. Hammond D, Daniel S, White CM. The effect of cigarette branding and plain packaging on female youth in the United Kingdom. $J$ Adolesc Health 2013;52:151-7.

22. Choi K, Fabian L, Mottey N, et al. Young adults' favorable perceptions of snus, dissolvable tobacco products, and electronic cigarettes: findings from a focus group study. Am J Public Health 2012;102:2088-93.

23. Liu ST, Nemeth JM, Klein EG, et al. Adolescent and adult perceptions of traditional and novel smokeless tobacco products and packaging in rural Ohio. Tob Control 2014;23:209-14.

24. Adkison SE, Bansal-Travers M, Smith DM, et al. Impact of smokeless tobacco packaging on perceptions and beliefs among youth, young adults, and adults in the US: findings from an internet-based cross-sectional survey. Harm Reduct J 2014;11:2.

25. Pedersen $\mathbf{W}$, von Soest $\mathrm{T}$. Tobacco use among Norwegian adolescents: from cigarettes to snus. Addiction 2014;109:1154-62.

26. Lund KE, McNeill A. Patterns of dual use of snus and cigarettes in a mature snus market. Nicotine Tob Res 2013;15:678-84.

27. Lund I, Scheffels J. Adolescent tobacco use practices and user profiles in a mature Swedish moist snuff (snus) market: Results from a school-based cross-sectional study. Scand J Public Health 2016. (Epub ahead of print)

28. Silverman D. Interpreting qualitative data: methods for analyzing talk text and interaction. Thousand Oaks, CA: Sage Publications, 2010. 
29. Davidson PW. The third person effect in communication. Public Opin Q 1983;47:1-15.

30. Edvardsson I, Troein M, Ejlertsson G, et al. Snus user identity and addiction. A Swedish focus group study on adolescents. BMC Public Health 2012;12:975.

31. Mejia AB, Ling PM. Tobacco industry consumer research on smokeless tobacco users and product development. Am J Public Health 2010;100:78-87.

32. Hulberg J. Integrating corporate branding and sociological paradigms: a literature study. J Brand Manag 2006;14: $60-73$.
33. Lewis MJ, Wackowski O. Dealing with an innovative industry: a look at flavored cigarettes promoted by mainstream brands. Am J Public Health 2006;96:244-51.

34. Kostygina G, Glantz SA, Ling PM. Tobacco industry use of flavours to recruit new users of little cigars and cigarillos. Tob Control 2016;25:66-74

35. White CM, Hammond D, Thrasher JF, et al. The potential impact of plain packaging of cigarette products among Brazilian young women: an experimental study. BMC Public Health 2012;12:737.

36. Hoek J, Robertson C. How do young adult female smokers interpret dissuasive cigarette sticks? A qualitative analysis. J Soc Mark 2015; 5:21-39. 